\title{
Identification and characterization of the novel Col10a1 regulatory mechanism during chondrocyte hypertrophic differentiation
}

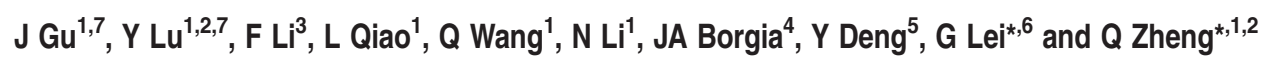

The majority of human skeleton develops through the endochondral pathway, in which cartilage-forming chondrocytes proliferate and enlarge into hypertrophic chondrocytes that eventually undergo apoptosis and are replaced by bone. Although at a terminal differentiation stage, hypertrophic chondrocytes have been implicated as the principal engine of bone growth. Abnormal chondrocyte hypertrophy has been seen in many skeletal dysplasia and osteoarthritis. Meanwhile, as a specific marker of hypertrophic chondrocytes, the type $\mathrm{X}$ collagen gene (COL10A1) is also critical for endochondral bone formation, as mutation and altered COL10A1 expression are often accompanied by abnormal chondrocyte hypertrophy in many skeletal diseases. However, how the type $X$ collagen gene is regulated during chondrocyte hypertrophy has not been fully elucidated. We have recently demonstrated that Runx2 interaction with a 150-bp mouse Col10a1 cis-enhancer is required but not sufficient for its hypertrophic chondrocyte-specific reporter expression in transgenic mice, suggesting requirement of additional Col10a1 regulators. In this study, we report in silico sequence analysis of this 150-bp enhancer and identification of its multiple binding factors, including AP1, MEF2, NFAT, Runx1 and TBX5. Using this enhancer as bait, we performed yeast one-hybrid assay and identified multiple candidate Col10a1-interacting genes, including cyclooxygenase 1 (Cox-1) and Cox-2. We have also performed mass spectrometry analysis and detected EF1-alpha, Fus, GdF7 and Runx3 as components of the specific complex formed by the cis-enhancer and nuclear extracts from hypertrophic MCT (mouse chondrocytes immortalized with large T antigen) cells that express Col10a1 abundantly. Notably, some of the candidate genes are differentially expressed in hypertrophic MCT cells and have been associated with chondrocyte hypertrophy and Runx2, an indispensible Col10a1 regulator. Intriguingly, we detected high-level Cox-2 expression in hypertrophic MCT cells. Electrophoretic mobility shift assay and chromatin immunoprecipitation assays confirmed the interaction between Cox-2 and Col10a1 cis-enhancer, supporting its role as a candidate Col10a1 regulator. Together, our data support a Cox-2-containing, Runx2-centered Col10a1 regulatory mechanism, during chondrocyte hypertrophic differentiation. Cell Death and Disease (2014) 5, e1469; doi:10.1038/cddis.2014.444; published online 16 October 2014

The human skeleton is divided into two main groups: the axial (skull, vertebral column and ribs) and the appendicular (shoulder girdles and limb long bones) skeleton. Most of the skeleton develops through a pathway called endochondral ossification, which involves a cartilage intermediate. In this pathway, the mesenchymal cells condense and form chondrocytes, chondrocytes continue to differentiate, proliferate and enlarge into hypertrophic chondrocytes. Hypertrophic chondrocytes have been implicated as the principal engine and master regulatory cells for bone growth, as these cells are associated with blood vessel invasion and are surrounded by a calcified extracellular matrix that favors endochondral ossification. $^{1-3}$
The type $X$ collagen gene (COL10A1) is specifically expressed by hypertrophic chondrocytes. As a major component of hypertrophic zone, type $X$ collagen influences deposition of other matrix molecules to this region and thereby provide a proper environment for hematopoiesis, mineralization and modeling that are essential for endochondral ossification. ${ }^{4,5}$ Mutations and abnormal expression of COL10A1 are closely linked to abnormal chondrocyte hypertrophy that has been seen in multiple skeletal dysplasia and osteoarthritis. ${ }^{6-15}$ Schmid metaphyseal chondrodysplasia (SMCD) is an autosomal dominantly inherited skeletal disorder caused by human COL1OA1 mutation. SMCD is characterized by short stature, coxa vara and an irregular

\footnotetext{
${ }^{1}$ Department of Hematology and Hematological Laboratory Science, School of Medical Science and Laboratory Medicine, Jiangsu University, Zhenjiang, China; 2Department of Anatomy and Cell Biology, Rush University Medical Center, Chicago, IL, USA; ${ }^{3}$ Department of Pathophysiology, Anhui Medical University, Hefei, China; ${ }^{4}$ Department of Pathology and Department of Biochemistry, Rush University Medical Center, Chicago, IL, USA; ${ }^{5}$ Department of Internal Medicine and Biochemistry, Rush University Medical Center, Chicago, IL, USA and ${ }^{6}$ Department of Orthopaedic Surgery, Xiangya Hospital, Central South University, Changsha, China

*Corresponding authors: G Lei, Department of Orthopaedic Surgery, Xiangya Hospital, Central South University, Changsha 410008, China. Tel: +86 731 84327326 ; Fax: +86 731 84327332; E-mail: Igh9640@ sina.com

or Q Zheng, Department of Anatomy and Cell Biology, Rush University Medical Center, Chicago, IL 60612, USA. Tel: +1 3129425514 ; Fax: +1 3129425744 ; E-mail: qiping_zheng@ @ush.edu

${ }^{7}$ These authors contributed equally to this work.

Abbreviations: SMCD, Schmid metaphyseal chondrodysplasia; CCD, cleidocranial dysplasia; TF, transcription factor; TRAP, transcription factor affinity prediction; MCT cells, mouse chondrocytes immortalized with large T antigen; Cox-2, cyclooxygenase 2; Y1H, yeast one-hybrid screening; ChIP, chromatin immunoprecipitation; TFBS, transcription factor binding sites; EMSA, electrophoretic mobility shift assay; IHC, immunohistochemistry; TG, Transgenic

Received 11.7.14; revised 02.9.14; accepted 03.9.14; Edited by A Stephanou
} 
growth plate, suggesting defective endochondral bone formation, whereas Col10a1 null mice have compressed growth plate similar to human SMCD. ${ }^{6,16-18}$ Cleidocranial dysplasia (CCD) is another autosomal dominant skeletal dysplasia caused by haploinsufficiency of RUNX2, a known master transcription factor (TF) for osteoblast differentiation and chondrocyte maturation. ${ }^{19-24}$ We have previously shown that CCD has defective endochondral ossification (short stature and cone epiphyses) with decreased COL10A1 expression and markedly diminished hypertrophic zone. ${ }^{11}$ As to the correlation of COL1OA1 expression and chondrocyte hypertrophy with osteoarthritis, it was previously reported that human osteoarthritic cartilage showed upregulated COL10A1 expression and enhanced chondrocyte hypertrophy, whereas mesenchymal stem cells from patients with osteoarthritis constitutively express type $X$ collagen. ${ }^{7,8,25,26}$

The above findings demonstrate the significant clinical relevance of collagen $\mathrm{X}$ expression with skeletal development and disease. Previously, extensive studies have identified multiple TFs or signaling pathways that contribute to type $X$ collagen gene regulation. These include TFs AP1, carbonic anhydrase (CA) IX, GADD45beta, HIF-2a, MEF-2C, PTH/ PTHrP, SOX9, SP3/SP1 and the Bmp/lhh/Wnt signaling pathways. ${ }^{13,27-35}$ Notably, most of these factors interact with the proximal promoter of type $\mathrm{X}$ collagen gene. We have been working on murine Col10a1 gene regulation and have demonstrated that Runx2 contributes to hypertrophic chondrocyte-specific Col10a1/reporter expression in vivo through interaction with both the proximal promoter and the distal enhancer element (150-bp, -4296 to -4147$).{ }^{36-38}$ However, our data also suggest that other regulators, in addition to Runx2, are needed to specify Col10a1 promoter activity. In this paper, we report identification and characterization of these regulators by dissection of the 150-bp enhancer using comprehensive bioinformatics, proteomics and transgenic (TG) approaches.

\section{Results}

Col10a1 enhancer versus nonspecific promoter element in TG studies. We have previously generated multiple TG mouse lines using different Col10a1 promoter and enhancer elements to drive the $L a c Z$ gene. Varied levels of $L a c Z$ reporter expression (shown by X-gal blue staining intensity) was observed in these TG mice. ${ }^{36,37}$ We have performed detailed analysis of mice from the $T g-4 \times 150$ and the $T g-10 \mathrm{~kb}$ TG lines. The Tg-4x150 construct contains only 150-bp Col10a1 cis-enhancer (four copies) and the basal promoter, whereas the $T g-10 \mathrm{~kb}$ contains both the enhancer and large promoter/intron elements to drive the LacZ gene (Figure 1a). The results showed that the $T g-4 \times 150$ mice drive much stronger reporter activity exclusively in hypertrophic a

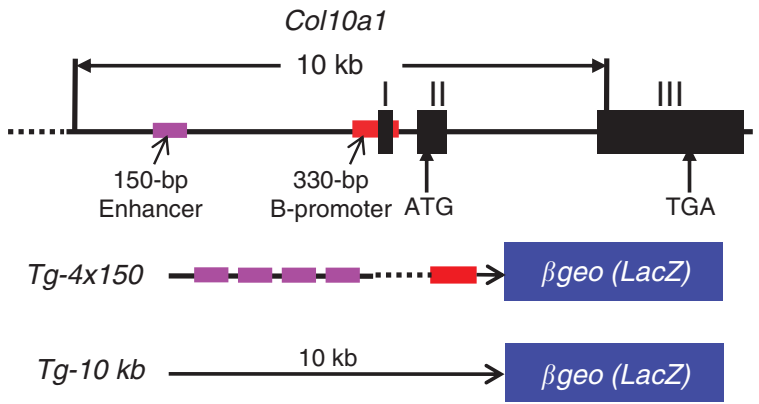

b
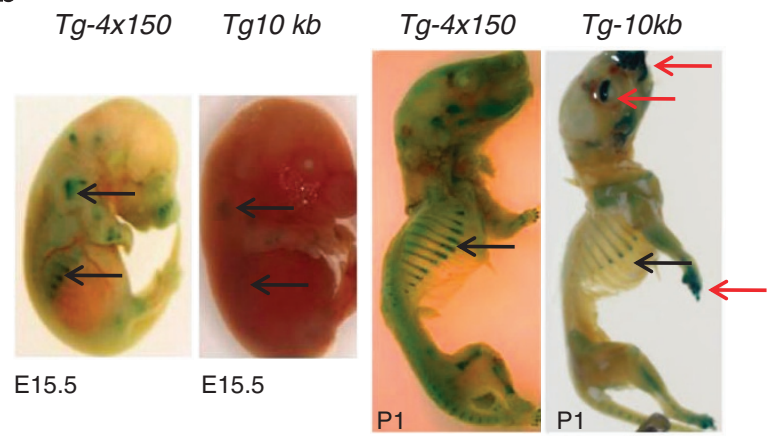

C

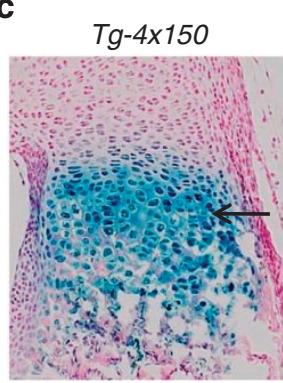

Prox-ulna

d

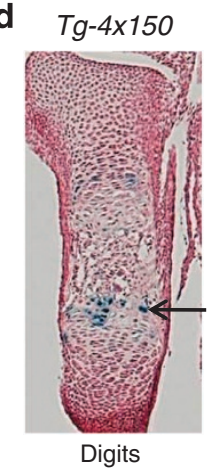

$\operatorname{Tg}-10 \mathrm{~kb}$

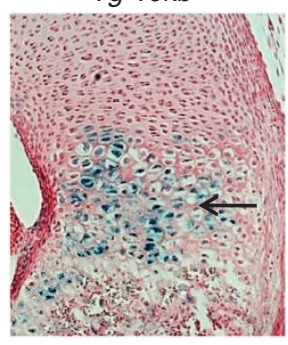

Prox-ulna

$\operatorname{Tg}-10 \mathrm{~kb}$

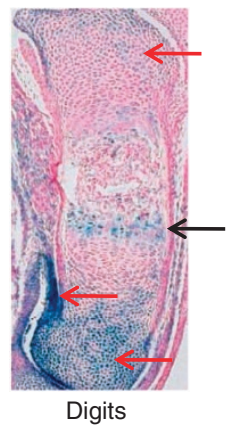

Figure 1 Detailed analysis of $T g-4 \times 150$ and $T g-10 \mathrm{~kb}$ TG reporter mice. (a) Top panel displays Col10a1 gene structure and the 10 -kb promoter and intronic element. Positions of the 150-bp ( -4296 to -4147 bp) Col10a1 cis-enhancer (purple bar) and its 330-bp ( -220 to +110 bp) basal promoter (red bar) are shown. Bottom panel shows the different Col10a1 promoter/enhancer element to drive the LacZ reporter gene. (b) X-gal staining and comparison between TG mice Tg-4x150 and Tg-10 kb at both E15.5 (left panel) and P1 (right panel) stages. Much stronger and more specific staining was detected in $\mathrm{Tg}-4 \times 150$ mice, whereas $\mathrm{Tg}-10 \mathrm{~kb}$ mice show extra nonspecific staining in digits and craniofacial region (red arrows). (c) Histochemical analysis of the limb sections (proximal ulna) confirmed much stronger blue staining in the hypertrophic zone of $\mathrm{Tg}$-4x150 mice than in $T g-10 \mathrm{~kb}$ mice (black arrows). (d) Analysis of the digit sections detect extra nonspecific blue staining in resting chondrocytes of $T g$ - $10 \mathrm{~kb}$ mice (red arrows), but not in $\operatorname{Tg}-4 \times 150$ mice 
a

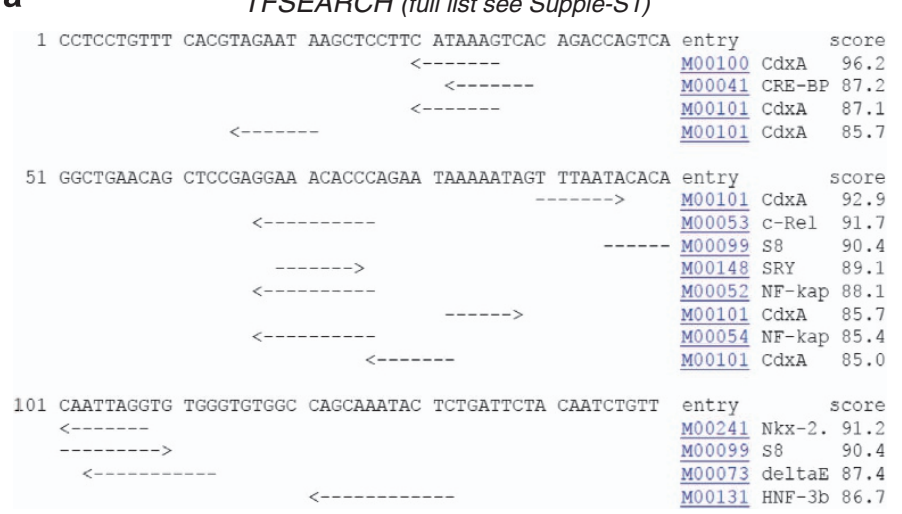

c

\begin{tabular}{|c|c|c|c|c|c|c|}
\hline Rank & P-value & Corrected p-value & Matrix ID & Matrix name & Affinity Plot & Binding Sites \\
\hline 1 & 0.00153 & 0.737 & M00395 & VS\$HOXA3_01 & Graph & Sites \\
\hline 2 & 0.00317 & 0.737 & M01440 & V\$LLHX8_01 & \begin{tabular}{|l|} 
Graph \\
\end{tabular} & Sites \\
\hline 3 & 0.00327 & 0.737 & M01331 & V\$ISX_01 & Graph & Sites \\
\hline 4 & 0.00406 & 0.737 & M01421 & V\$LLHX4_01 & Graph & Sites \\
\hline 5 & 0.00526 & 0.737 & M00403 & V\$़AMEF2_Q6 & Graph & Sites \\
\hline 6 & 0.00646 & 0.737 & MO0150 & V\$BRACH_O1 & Graph & Sites \\
\hline 7 & 0.00675 & 0.737 & M01386 & V\$SEVX2_01 & Graph & Sites \\
\hline 8 & 0.0083 & 0.737 & M01371 & V\$GBX1_01 & Graph & Sites \\
\hline 9 & 0.00981 & 0.737 & Mo1113 & V\$CACD 01 & Graph & Sites \\
\hline 10 & 0.0142 & 0.737 & M01162 & V\$OG2_01 & Graph & Sites \\
\hline
\end{tabular}

b

PROMO (full list see Supple-S2)

$\begin{array}{clrl}1 & \text { FACB [T02841] } & 2 & \text { BTEB3 [T05051] } \\ 9 & \text { HNF-3beta [T01049] } & 10 & \text { Msx-1 [T02072] } \\ 17 & \text { POU1F1a [T00691] } & 18 & \text { C/EBPdelta [T00109] } \\ 25 & \text { HOXD8 [T01426] } & 26 & \text { HOXD8 [T01754] } \\ 33 & \text { AP-1 [T00029] } & 34 & \text { AP-1 [T00032] } \\ 41 & \text { TFIIB [T00818] } & 42 & \text { Pax-2a [T00678] } \\ 49 & \text { AP-2alphaA [T00035] } & 50 & \text { NF-1 (-like) [T00601] } \\ 57 & \text { CREMtau2 [T02109] } & 58 & \text { myogenin [T00528] } \\ 65 & \text { HELIOS [T06012] } & 66 & \text { Elk-1 [T00250] } \\ 73 & \text { ABI4 [T05743] } & 74 & \text { Pax-9a [T03593] } \\ 81 & \text { Cutl1 [T02042] } & 82 & \text { AGL3 [T03025] } \\ 89 & \text { Nkx6-2 [T02050] } & 90 & \text { FOXF1 [T02461] } \\ 97 & \text { aMEF-2 [T01006] } & 98 & \text { SBF-1 [T00739] }\end{array}$

d

\begin{tabular}{|c|c|c|c|c|c|}
\hline Matrix Id & Position(Strand) & $\begin{array}{l}\text { Core } \\
\text { Score }\end{array}$ & $\begin{array}{l}\text { Matrix } \\
\text { Score }\end{array}$ & Sequence & $\begin{array}{l}\text { Factor } \\
\text { Name }\end{array}$ \\
\hline VSTSTI_O1 & $76(t)$ & 0.929 & 0.903 & ccaGAATAaaaatag & Tst-1 \\
\hline VSRSRFC4_Q2 & $78(t)$ & 1 & 0.905 & agaataaaAATAGttta & RSRFC4 \\
\hline VSFOXJI__O2 & $81(t)$ & 0.897 & 0.905 & ataAAAATagttta & FOXJ2 \\
\hline V\$OG__O1 & $102(\cdot)$ & 1 & 1 & CAATTA & $O G-2$ \\
\hline VSTBXS_OO1 & $105(t)$ & 1 & 0.972 & ttaGGTGTgggt & TBX5 \\
\hline VSCACD_01 & $113(-)$ & 1 & 1 & GGGTGtgg & $C A C D$ \\
\hline
\end{tabular}

Figure 2 Bioinformatics prediction of TFBS within 150-bp Col10a1 cis-enhancer. (a) TFSEARCH with a cutoff score of 85 identified 15 putative TFBSs including CdxA (six times), C-Rel, S8 (twice) and Nkx-2 etc (see also Supplementary Data S1). (b) Promo 3.0 program (with 85 similarity) identified approximately 200 putative TFs, including many AP1s (c-fos, c-Jun, ATF and JDP families), Hif and $\alpha$ MEF-2 (see also Supplementary Data S2). (c) TRAP identified approximately 50 TFs that showed a $P$-value $<0.05$, including Hoxa3, CACD and $\alpha$ MEF-2 (see also Supplementary Data S3). (d) The MATCH program (with a matrix score of 90) identified six putative TFs including Tst-1, RSRFC4, FOXJ2, OG-2, TBX5 and CACD (see also Supplementary Data S4)

chondrocytes than that of $T g-10 \mathrm{~kb}$ mice as demonstrated by whole embryo staining at both E15.5 and P1 stages (Figure 1b) and by histochemical analysis of the limb sections (Figure 1c). There was nonspecific blue staining in resting chondrocytes of the craniofacial and digits of the $T g-10 \mathrm{~kb}$ mice, but not in $T g-4 \times 150$ mice (Figures $1 \mathrm{~b}$ and $\mathrm{d}$ ). These results show that multiple copies of the enhancer (150-bp Col10a1 distal promoter) mediates higher level and cellspecific reporter activity, whereas the 10-kb Col10a1 promoter/intronic element contains nonspecific regulatory elements, in addition to the 150-bp enhancer.

Predictive candidate genes. We used multiple web-based programs to search for transcription factor binding sites (TFBSs) within the 150-bp enhancer. The TFSEARCH program identified 16 putative Col10a1-interacting factors with a cutoff score of 85 , whereas only 6 putative TFBSs are shown (CdxA x 2, C-Rel, S8 x 2 and Nkx-2) when the cutoff score was increased to 90 (Figure 2a, Supplementary Data S1). ${ }^{39,40}$ Nearly 200 putative TFs were predicted to bind this cis-enhancer using the Promo 3.0 and TRANSFAC database (version 8.3). ${ }^{41,42}$ These factors include those identified by TFSEARCH and many AP1s (c-fos, c-Jun, ATF and JDP families), Hif and aMEF-2 (Figure $2 b$, Supplementary Data S2). We also use the TRAP software to predict putative binding factors. ${ }^{43}$ TRAP provides affinitybased ranking of TFs with a $P$-value. We identified approximately 50 TFs that showed a $P$-value $<0.05$, including Hoxa3, CACD and aMEF-2 (Figure 2c, Supplementary Data S3). Finally, the MATCH program identified six putative TFs (Tst-1, RSRFC4, FOXJ2, OG-2, TBX5 and CACD) by searching the TRANSFAC database (updated version 10.1, BIOBASE) for TFBS with a matrix score of 90 (Figure 2d, Supplementary Data S4). ${ }^{44,45}$ It is not surprising that the short AT-rich TFs (such as CdxA site: CATAAAG) were identified by multiple programs. Intriguingly, some developmentally important genes, including MEF-2s, Pax family members and Tbx5, were also identified by above dual or triple programs (Figure 2 and Supplementary Data S1-S4).

Candidate genes identified by yeast one-hybrid $(\mathrm{Y} 1 \mathrm{H})$ screening. Tandem copies of the 150-bp enhancer elements were successfully cloned into the pHis2.1 vector (Clontech, Mountain View, CA, USA; K1617-1) upstream of the nutritional reporter HIS3 (Figure $3 a$ ). This reporter construct was used as a bait to screen the cDNA library derived from hypertrophic MCT (mouse chondrocytes immortalized with large $T$ antigen) cells by co-transformation with pGADT7Rec2 expression vector in the $\mathrm{Y} 187$ yeast competent cells. Approximately, 50 yeast colonies grown in selective medium 
a

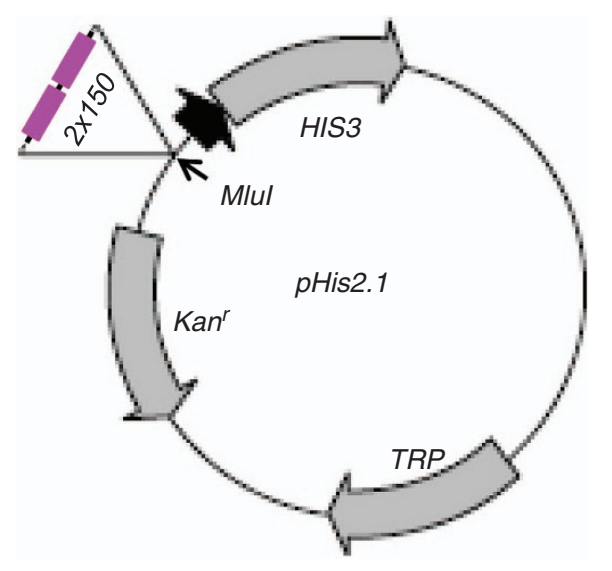

b

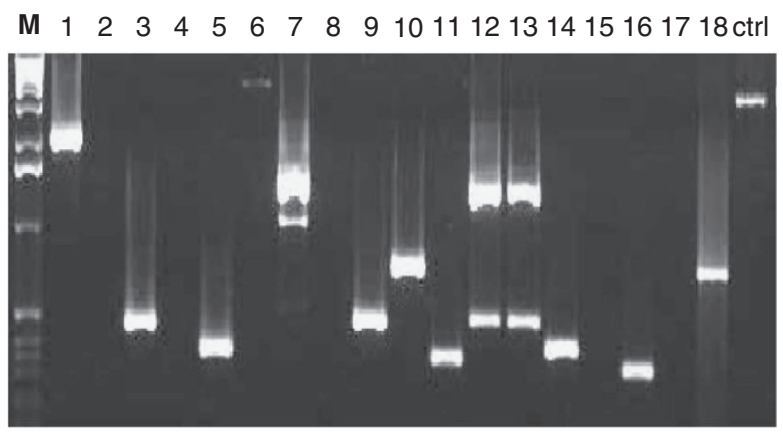

c
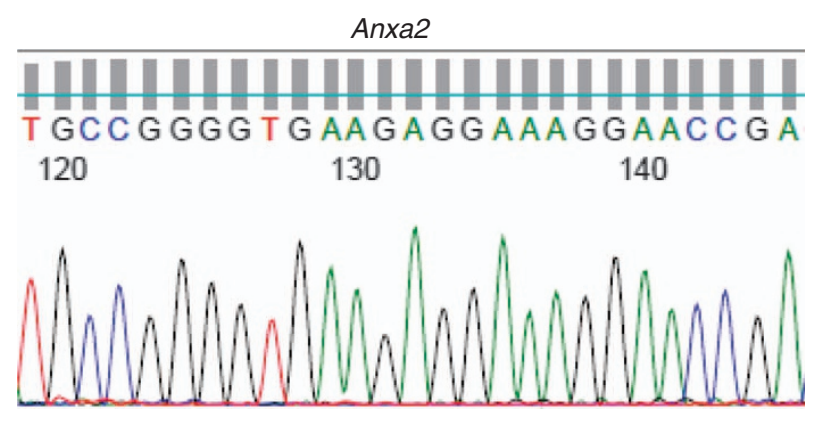

d

\begin{tabular}{l|ll}
\hline Gene Name & \multicolumn{1}{|c}{ Function } & \multicolumn{1}{c}{ Reference } \\
\hline Anxa2 & Annexin A2, Apoptosis & Waters et al., 2013 \\
Fn1 & Fibronectin1, Wnt signaling & Bentzinger et al., 2013 \\
Hspa5 & Also GRP78, cell growth & Zhu et al., 2013 \\
Nedd4 & E3 ligase, Neural develop. & Kwak et al., 2012 \\
Psmb1 & Gastrin regulation & O'Hara et al., 2013 \\
Ptgs2 & Chondrocyte hypertrophy & Welting et al., 2011 \\
Rab1 & Ras oncogene family & Nabavi et al., 2012 \\
Rela & Also P65, inflammation & Waddell et al., 2013 \\
Rpl35 & Ribosomal protein L35 & Gazda et al., 2012 \\
Rps28 & Ribosomal protein s28 & Kondrashov et al 2013 \\
\hline
\end{tabular}

Figure 3 Y1H screening using the 150-bp enhancer as a bait. (a) The 150-bp Col10a1 cis-enhancer (tandem copies, $2 \times 150$ ) was cloned upstream of the nutritional reporter gene HIS3 in a pHis2.1 vector backbone (Clontech). (b) After screening a cDNA library derived from hypertrophic MCT cells, approximately 50 yeast colonies grown in selective medium and optimal 3-AT concentration were selected and subjected to PCR amplification. (c) Representative sequencing result of the PCR product shows partial sequence of exon II of gene Anxa2. (d) A list of candidate genes identified by Y1H were shown. These genes include Fn1, Hspa5, Nedd4, Psmb1, Ptgs2, Rab1, Rela, Rpl35 and Rps28. The functional description and relevant literatures were as listed

and optimal 3-AT concentration were selected and subjected to PCR and sequencing (Figures $3 \mathrm{~b}$ and $\mathrm{c}$ ). After searching with the NCBI database, we identified multiple candidate Col10a1-interacting genes as listed (Anxa2, Fn1, Hspa5, Nedd4, Psmb1, Ptgs2, Rab1, Rela, Rpl35 and Rps28). The putative function of these genes and the relevant literatures are as summarized (Figure $3 d$ ).

Candidate genes identified by mass spectrometry. We have previously shown that a short DNA element $(-4196$ to $-4172 \mathrm{bp}$ ) from the Col10a1 cis-enhancer can form specific binding complex with hypertrophic MCT cell nuclear extracts (Figure $4 a){ }^{38}$ We have performed tandem mass spectrometry analysis on above binding mixture and identified $>90$ putative factors after searching with the SwissProt 51.6 (protein) database. These factors meet the criteria for protein identification that reaches a minimum MASCOT score of 35 with at least 5 matched peptides. Illustrated are Fus (a RNAbinding protein) and Gdf7 (growth differentiation factor 7) that are potential components of the binding complex (Figures $4 \mathrm{~b}$ and $\mathrm{c}$ ). Candidate factors with certain MASCOT score and matched peptides are as listed (Figure 4d, Supplementary Data S5). These include genes Ddef2, Foxk2, Fus, Gdf7, Hnf3a, N4bp3, Rab28, Scrt2, Sfrp4 and Tgm1 etc.
Expression analysis of candidate genes. To characterize the candidate Col10a1 regulators identified by bioinformatics and proteomic approaches, we examined their correlation with Col10a1 expression in MCT cells, which are mouse chondrocytes immortalized by SV40 large $T$ antigen. ${ }^{46}$ MCT cells show properties of chondrocyte hypertrophy (increased level of Runx2 and other marker genes) and significantly upregulated Col10a1 mRNA transcript ( 10-fold) upon growth arrest (from 32 to $37^{\circ} \mathrm{C}$; Figure $5 \mathrm{a}$ ). The results showed that most predictive candidate genes identified by MATCH program (Foxj2, KIf3/Tef-2/Cacd, Mef2a/RSRFC4 and Nobox/Og-2) were upregulated in hypertrophic MCT cells compared with proliferative MCT cells, whereas Pou3f1Tst-1 and $\mathrm{Tb} \times 5$ showed no difference or was not detected in neither of the MCT cells (Figure $5 b$ ). Analysis of 10 of the candidate genes identified by $\mathrm{Y} 1 \mathrm{H}$ showed that Fn1, Hspa5, Psmb1, Ptgs2/cyclooxygenase 2 (Cox-2), Rab1 and Rps28 genes were significantly upregulated upon growth arrest $(P<0.05)$, whereas genes Anxa2, Nedd4, Rela and Rp/35 showed no difference $(P>0.05$, Figure 3c). Ten candidate genes identified by MS were analyzed. Only Scrt2 and Sfrp4 genes are significantly upregulated, whereas Fus gene is significantly downregulated in hypertrophic MCT cells, other genes showed no difference (Figure 5d). 
a

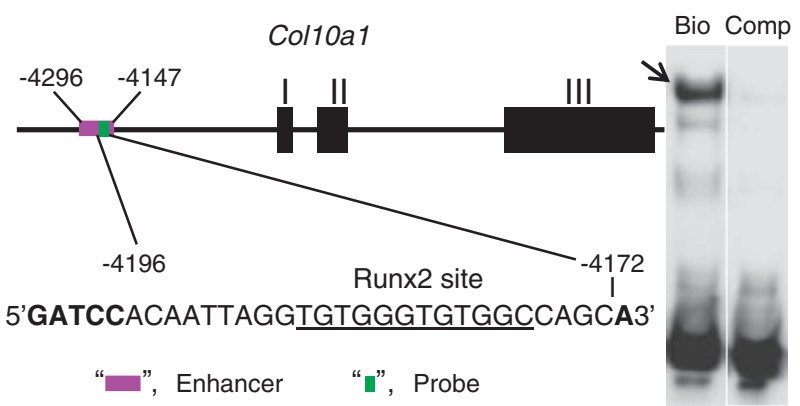

b

Fus

1 MASNDYTQQA TQSYGAYPTQ PGQGYSQQSS QPYGQQSYSG YGQSADTSGY 51 GQSSYGSSYG QTQNTGYGTQ SAPQGYGSTG GYGSSQSSQS SYGQQSSYPG 101 YGQQPAPSST SGSYGGSSQS SSYGQPQSGG YGQQSGYGGQ QQSYGQQQSS 151 YNPPQGYGQQ NQYNSSSGGG GGGGGGYGQ DQSSMSGGG GGGYGNQDQS 201 GGGGGGYGGG QQDRGGRGRG GGGGYNRSSG GYEPRGRGG RGGRGGMGGS 251 DRGGFNKFGG PRDQGSRHDS EQDNSDNNTI FVQGLGENVT IESVADYFKQ 301 IGIIKTNKKT GQPMINLYTD RETGKLKGEA TVSFDDPPSA KAAIDWEDGK 351 EFSGNPIKVS FATRRADFNR GGGNGRGGRG RGGPMGRGGY GGGGSGGGGR 401 GGFPSGGGGG GGQQRAGDWK CPNPTCENMN FSWRNECNQC KAPKPDGPGG 451 GPGGSHMGGN YGDDRRGRGG YDRGGYRGRG GDRGGFRGGR GGGDRGGFGP 501 GKMDSRGEHR QDRRERPY

c

Gdf7

1 MDLSAAAALC LWLLSACRPR DGLEAAAVLR AAGAGPAWSP GGGGGGRTLA 51 RAPGPSALQA AAVPGPRAVR RAAGSGERNG SVVPHHEMMS LYRSLAGRAP 101 VAAASGHGRV DTITGETDQA TQDETAAAEP GQSFLFDVSS LSEADEVVNA 151 ELRVLRRRSP EPDRDSATLL PRLLLSTCPD EAGTAHLLHS RAAEPLGGAR 201 WEAFDVTDAV QSHRRWPRAS RKECLVLRAV TASESSPLAL RRLGFGWPGG 251 GDGGGTAAEE RALLVISSRT QRKESLIREI RAQARALRAA AEPPPDPGPG 301 AGSRRANLGG RRRRRTALAG TRGAQGSGGG GGGGGGGGGG GGGGGGGAGR 351 GHGRRGRSRC SRKSLHVDEK ELGWDDWIIA PLDYEAYHCE GVCDFPLRSH 401 LEPTNHAIIQ TLINSMAPDA APASCCVPAR LSPISILYID AANNVYYKQY 451 EDMVVEACGC R

d

Candidate Col10a1 regulators identified by MS

\begin{tabular}{l|lcc}
\hline $\begin{array}{c}\text { Gene } \\
\text { Name }\end{array}$ & \multicolumn{1}{|c}{ Gene description } & $\begin{array}{c}\text { Mascot } \\
\text { Score }\end{array}$ & $\begin{array}{c}\text { Matched } \\
\text { Peptide }\end{array}$ \\
\hline Ddef2 & Dev. \& diff. enhancing factor 2 & 36 & 6 \\
Foxk2 & Forkhead box protein k2 & 37 & 7 \\
Fus & RNA-binding protein FUS & 44 & 39 \\
Gdf7 & Growth differentiation factor 7 & 53 & 73 \\
Hnf3a & Hepatocyte nuclear factor 3-a & 38 & 27 \\
N4bp3 & NEDD4-binding protein 3 & 36 & 9 \\
Rab28 & Member Ras oncogene family & 35 & 5 \\
Scrt2 & Transcriptional repressor scratch 2 & 42 & 22 \\
Sfrp4 & Secreted frizzle-related protein 4 & 37 & 6 \\
Tgm1 & Gamma-glutamyltransferase K & 35 & 20 \\
\hline
\end{tabular}

Figure 4 Mass spectrometry analysis of specific DNA/protein complex. (a) Position and sequence of the DNA probe from the enhancer region are shown. ${ }^{38}$ Bio-tin labeled cis-element containing the Runx2 site (underlined) can form specific complex with hypertrophic MCT cell nuclear extracts (arrow), whereas no binding complex was observed when using the unlabeled competitive control. (b) Fus was identified as it met the criteria for protein identification, that is MASCOT $>=35$ with $>=5$ matched peptides (red letters). (c) Gdf7 also meets the criteria for protein identification. (d) Partial list of genes that encode proteins and meet the criteria for protein identification. These include genes Ddef2, Foxk2, Fus, Gdf7, Hnf3a, N4bp3, Rab28, Scrt2, Sfrp4 and Tgm1. Gdf7 has the highest (53) MASCOT score with the most (73) matched peptides

a

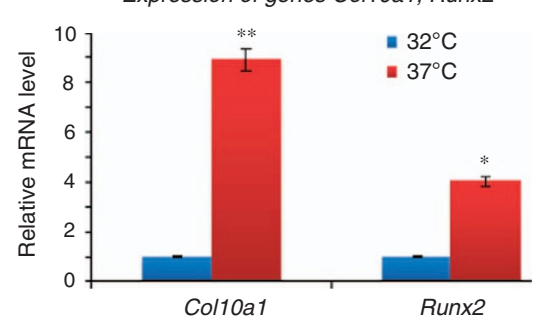

b

Expression of predictive candidate genes

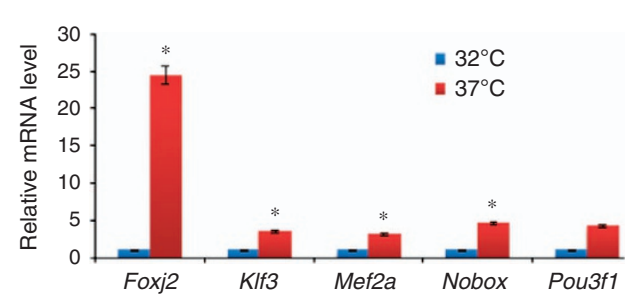

C Expression of candidate genes from $\mathrm{Y} 1 \mathrm{H}$
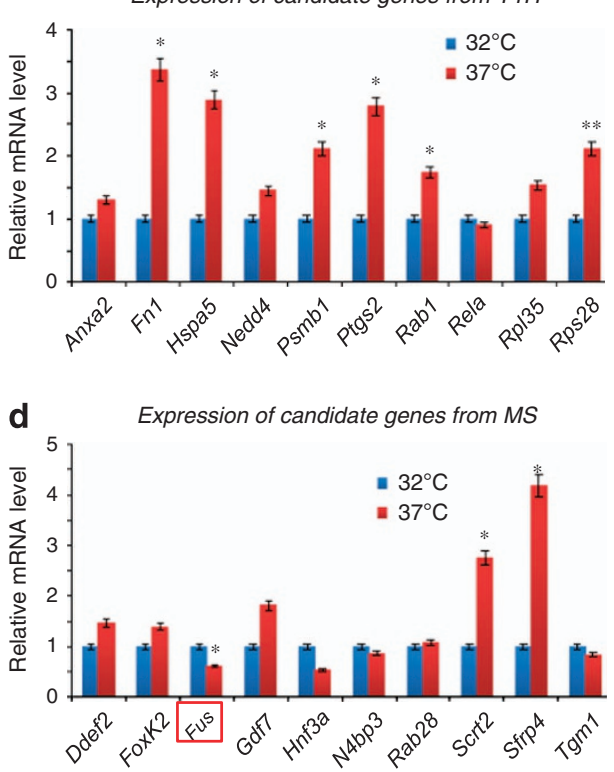

Figure 5 Expression analysis of candidate genes in MCT cells. (a) qRT-PCR was performed to examine the mRNA transcript level of marker genes Col10a1 and Runx2 in MCT cells. As illustrated, both Col10a1 (8.8-fold, $P=0.009)$ and Runx2 (4.0-fold, $P=0.04)$ are significantly upregulated in hypertrophic MCT cells compared with that in proliferative MCT cells. ${ }^{*} P<0.05$; ${ }^{\star *} P<0.01$. (b) Five candidate genes (Foxj2, Klf3, Mef2a, Nobox and Pou3f1) identified by Match program were examined. Except for Pou3f1 (3.9-fold, $P=0.06$ ), all other genes examined show significant upregulation in hypertrophic MCT cells. ${ }^{*} P<0.05$. (c) Ten candidate genes identified by $Y 1 \mathrm{H}$ were selected and examined. Genes Fn1, Hspa5, Psmb1, Ptgs2, Rab1 and Rps28 are significant upregulated in hypertrophic MCT cells, while others (Anxa2, Nedd4, Rela and Rpl35) showed no difference between hypertrophic and proliferative MCT cells. ${ }^{*} P<0.05$; ${ }^{* *} P<0.01$. (d) Ten candidate genes identified by MS were also selected and examined. Genes Scrt2 (2.8-fold, $P=0.024)$ and Sfrp4 (4.2-fold, $P=0.029)$ showed significant upregulation, whereas Fus was significantly downregulated $(0.6$-fold, $P=0.041)$ in hypertrophic MCT cells. Genes (Ddef2, FoxK2, Gdf7, Hnf3a, N4bp3, Rab28 and Tgm1) showed no difference between hypertrophic and proliferative MCT cells. ${ }^{*} P<0.05$ 
a

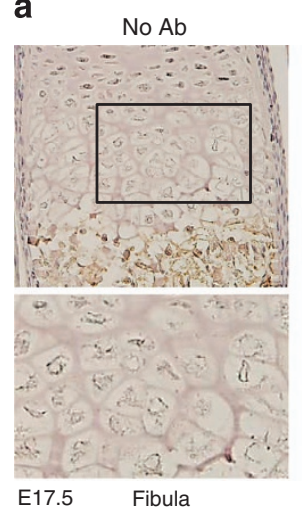

b

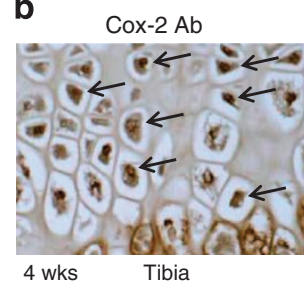

Cox-2 Ab

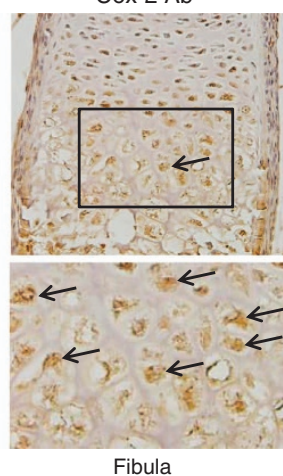

Col-X Ab

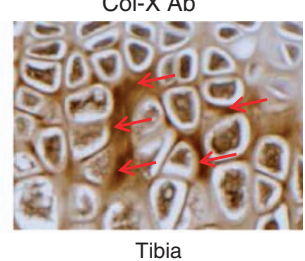

C
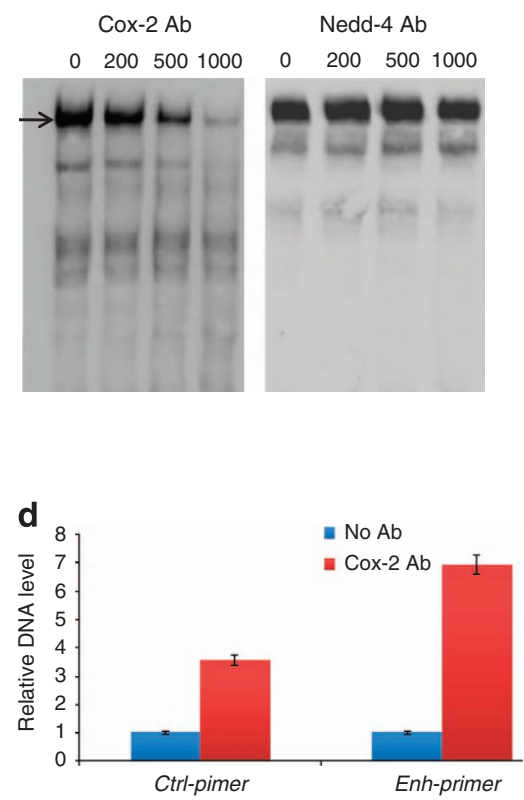

Figure 6 Cox-2 expression and interaction with Col10a1 cis-enhancer. (a) IHC assay using Cox-2 antibody on sagittal sections of mouse limb (fibula) at E17.5 showed that Cox-2 is strongly expressed in nuclei of hypertrophic chondrocytes but not in resting or proliferative chondrocytes (black box and arrows). Bottom showed higher magnification of the boxed area. Left panel shows no antibody control. (b) IHC assay using Cox-2 antibody on tibia sections at 4 weeks' age also detected high-level Cox-2 expression in nuclei of hypertrophic chondrocytes (left panel, black arrows). Right panel shows IHC assay of collagen X, which is mostly expressed extracellular within hypertrophic zone (red arrows). (c) EMSA assay detected specific binding complex (black arrow) formed by the Col10a1 enhancer and hypertrophic MCT cell nuclear extracts as previously described. ${ }^{38}$ The signal intensity decreased when $200 \mathrm{ng}$ of Cox-2 antibody was added, $500 \mathrm{ng}$ of antibody further reduced the signal, whereas $1000 \mathrm{ng}$ of antibody only showed faint signal (left panel). No signal reduction was seen in parallel experiment in which gradient amount of Nedd4 antibody was used (right panel). Data of non-biotinylated competitor control were not shown. (d) Illustrated is the result of ChIP experiment showing precipitated DNA enriched by Cox-2 antibody or control lgG. qPCR using primers flanking the enhancer suggested a significant enrichment ( 7-fold, $P=0.034)$ of the enhancer by Cox-2 antibody, whereas sequence flanking the intronic control region did not show significant enrichment ( 3-fold, $P=0.062)$

\section{Analysis of candidate Col10a1 regulator Cox-2 (Ptgs2).} Cox-2 is a candidate Col10a1-interacting factor identified by $\mathrm{Y} 1 \mathrm{H}$ screening and is significantly upregulated in hypertrophic MCT cells (Figures $3 d$ and $5 c$ ). We chose to further analyze Cox-2 by immunohistochemical (IHC) analysis using Cox-2 antibody and mouse embryonic (E17.5) long bone sections. The result showed that Cox-2 is strongly expressed in nuclei of hypertrophic chondrocytes but not in resting or proliferative chondrocytes (Figure 6a and data not shown). We also examined Cox-2 and collagen $X$ expression postnatally (4 weeks' age). High-level Cox-2 expression was also observed within the nuclei of hypertrophic chondrocytes, whereas collagen $X$ mostly expressed extracellular as expected (Figure 6b). We performed candidate electrophoretic mobility shift assay (EMSA) using the same DNA element form the Col10a1 cis-enhancer and hypertrophic MCT cell nuclear extracts with gradient Cox-2 antibody. ${ }^{38}$ As an effort to characterize the few candidate genes (here in Nedd4) identified by $\mathrm{Y} 1 \mathrm{H}$ as well as its associated N4bp3 (Nedd4binding protein), we chose to perform similar candidate EMSA assay using Nedd4 antibody. The result supports that Cox-2, but not Nedd4, is a component of the DNA/protein complex (Figure 6c). We also performed chromatin immunoprecipitation (ChIP) assay using Cox-2 antibody (or IgG control) and the MCT cells. The result showed that the target sequence containing the Col10a1 enhancer was significantly enriched ( $\sim$-fold, $P=0.034)$ by Cox-2 antibody, whereas no significant enrichment was shown for the control primers ( 3fold, $P=0.062$; Figure $6 \mathrm{~d}$ ), suggesting an in vivo interaction between Cox-2 and the Col10a1 cis-enhancer in MCT cells.

\section{Discussion}

Factors in addition to Runx2 are required for Col10a1 promote/enhancer activity. More than a decade ago, extensive studies focused on identification of the proximal promoter elements and their binding factors that can only mediate collagen $\mathrm{X}$ expression to certain level. ${ }^{47-50} \mathrm{~A}$ highly conserved Col10a1 distal promoter/enhancer element was later identified, which is able to mediate high-level hypertrophic chondrocyte-specific reporter expression in TG mice. ${ }^{51}$ We have recently narrowed down this enhancer to a 150 -bp region. ${ }^{37}$ We have shown that a tandem-repeat Runx2 sites within its $3^{\prime}$-end is required for its enhancer activity in vivo, as mutating the Runx2 sites abolished its ability to drive cell-specific reporter expression. ${ }^{38}$ Notably, neither the $5^{\prime}$-sequence nor its overlapping $3^{\prime}$-sequence containing the Runx2 sites was able to drive cell-specific reporter expression, suggesting requirement of this entire 150 -bp enhancer in mediating its enhancer activity. Interestingly, our detailed analysis revealed that the $T g-4 \times 150$ mice show higher and more specific reporter expression than that of the Tg-10kb mice (Figure 1). This result confirmed the 
specificity of this 150-bp enhancer, whereas the $10-\mathrm{kb}$ promoter/intronic elements contain nonspecific regulatory elements. The stronger reporter activity is most likely due to the multiple copies of the binding sites for important TFs (Runx2, AP1 etc.). ${ }^{27,28,38}$

Bioinformatics prediction of TFBS for Col10a1 cisenhancer. Identification of the 150-bp promoter as the genuine Col10a1 enhancer makes it practical to predict potential TFBS that are functionally important. ${ }^{52}$ TFSEARCH is a pioneer web-based program that uses the TFMATRIX TFBS profile database to predict potential TFBSs. ${ }^{53} \mathrm{We}$ identified several candidate factors including NF-kappaB, which has been shown to facilitate growth plate or longitudinal bone growth via BMP. ${ }^{54}$ The PROMO program was designed to search for known binding sites and TFs from the TRANSFAC database with updates. ${ }^{55}$ Among the 200 potential TFBSs, candidate factors AP1s, Hif and aMEF-2 were previously shown to regulate Col10a1 expression and chondrocyte hypertrophy. ${ }^{13,27,30,56,57}$ Interestingly, the TRAP program identified approimately 50 TFs with a $P$-value $<0.05$, including factors that were selected by both the TFSEARCH and the PROMO programs ( $\mathrm{dxA}$, Mef2 etc.). We only identified six potential TFs using the Match program (Figure 2d). We notice that the binding sites of TBX5 and CACD overlap with the tandem-repeat Runx2 sites, which we and others have previously characterized. ${ }^{38,58} \mathrm{Tbx} 5$, which was not detected in hypertrophic MCT cells, has been shown to have a role in limb development. ${ }^{59}$ It is possible that the predictive candidate genes, especially those selected only by one program with a $P$-value $>0.05$, may be false-positive Col10a1-interacting factors. More attention should be paid to those factors identified by multiple web-based programs.

Proteomic identification of novel interacting genes/ factors. Multiple candidate factors were identified using the 150-bp enhancer as bait to screen the cDNA library derived from hypertrophic MCT cells. Not surprisingly, some candidate factors, including Rela (orp65), have been suggested to interact with this enhancer (Figure 2). Interestingly, we also identified Ptgs2/Cox-2, which was not selected by either of the above web-based programs. However, Cox-2 has been associated with chondrocyte hypertrophy and shows interaction with Col10a1 cis-enhancer as described (Figure 6). ${ }^{60}$ Meanwhile, mass spectrometry analysis of the specific binding complex formed by the Col10a1 enhancer and the MCT cell nuclear extracts identified multiple putative Col10a1-binding factors. Although some unrelated factors may be pulled down because of nonspecific force, we did identify Hnf-3, N4bp3 (Nedd4-binding protein) and other factors that were selected by in silico sequence analysis. Interestingly, we identified Gdf7 with highest Mascot score and most matched peptides (Figures $4 \mathrm{c}$ and $\mathrm{d}$, Supplementary Data S4). This is intriguing, as Gdf7 is a secreted protein, making it unlikely a gene expression regulator. However, Gdf7 have been associated with chondrocyte hypertrophy although the mechanism is not clear yet. $^{61}$
Identification of TFBS using comprehensive bioinformatics/proteomics approaches. Using web-based program to predict TFBS based on literature-derived data is an alternative and can significantly increase the efficiency of wet-lab experiments. ${ }^{52}$ Theoretically, the predictive candidate genes are expected to interact with the Col10a1 enhancer and impact on Col10a1 expression and chondrocyte hypertrophy. Indeed, MEF2C, which was identified by several programs, has been shown to control bone development by activating genes of chondrocyte hypertrophy, including Col10a1, whereas AP1/Ctgf interaction promotes chondrocyte hypertrophy during endochondral ossification. ${ }^{50,56}$ Interestingly, Pax family members were also identified by both PROMO (Pax-2, 4, 6, 8 and 9; Supplementary Data S2) and TRAP (Pax-2, $P=0.0277$ and Pax-7, $P=0.0158$; Supplementary Data S3) programs, whereas Pax-1 and Pax-9 have been linked to limb development with Pax-1 acting as a negative regulator for chondrocyte maturation. ${ }^{62,63}$ However, there are many predictive genes that show no evidence of correlation with the enhancer activity. These genes are either due to false selection of the program, or awaiting characterization before drawing any conclusion. $\mathrm{Y} 1 \mathrm{H}$ approach is designed to screen for candidate genes interacting with cis-enhancer elements. In our studies, we were able to identify several genes (such as Rela/p65, Ptgs2) that are known to relate to chondrocyte hypertrophy during endochondral bone formation. ${ }^{54,60}$ Although Nedd4 was identified and may have a role in skeletal development, previous studies have suggested that Nedd4 is expressed in proliferating chondrocytes instead of hypertrophic chondrocytes. ${ }^{64}$ We did not detect difference of Nedd4 mRNA level in proliferative and hypertrophic MCT cells (Figure $5 \mathrm{c}$ ), while candidate EMSA assay did not support that Nedd4 is a component of the specific binding complex (Figure 6c). Owing to leaky expression of reporter gene, false-positive clones may be selected. Similar situation may occur for candidate genes identified by mass spectrometry, considering their related (or irrelevant) expression and function.

We notice that MCT cells are transformed cells, which may not be a perfect cell model to represent hypertrophic differentiation and Col10a1 upregulation and for the purpose of verification. ${ }^{46}$ However, we have performed expression analysis of most of the candidate genes in ATDC5 cells, another cell model of endochondral ossification, which also shows significant upregulation of Col10a1 after extended culture and/or by ITS (insulin, transferrin and sodium selenite) induction. ${ }^{65,66}$ Similar levels of candidate gene expression was detected in ATDC5 cells compared with that in MCT cells, although with some discrepancy (data not shown). Further characterization of these candidate genes using both MCT and ATDC5 cell models will help to define their function in relation to Col10a1 expression and chondrocyte hypertrophy in vitro (Figure 5). ${ }^{46}$

Cox-2 and Col10a1 expression and chondrocyte hypertrophy. As mentioned above, Cox-2 was only selected by $\mathrm{Y} 1 \mathrm{H}$ screening. This is intriguing, as Cox2 is a membranebinding enzyme containing no known DNA-binding property. However, there are multiple lines of evidence which suggest the importance of Cox-2 upon bone formation. Cox-2 was 
shown to regulate mesenchymal cell differentiation and has essential roles in bone repair, whereas Cox-2 inhibitor negatively affect bone fracture healing. ${ }^{67,68} \mathrm{Cox}-2$ has been shown to control chondrocyte hypertrophy through cross-talk with BMP-2 pathway. ${ }^{60}$ We detected exclusive Cox-2 expression within nuclei of hypertrophic chondrocytes at both embryonic and postnatal stages. The involvement of Cox-2 within the specific binding complex, the increased Cox-2 expression upon Col10a1 upregulation in hypertrophic MCT cells and the interaction between Cox-2 and Col10a1 enhancer within MCT cells support a role of Cox-2 in Col10a1 expression.

Multiple factors in a putative Col10a1 regulatory mechanism. Along with others, we have demonstrated the indispensible role of Runx2 in regulation of its cell-specific expression across species. ${ }^{36,38,69-71}$ As to mouse type $X$ collagen gene, multiple transcriptional regulators and signaling pathways have been shown to contribute to Col10a1 expression. These include AP1 family members, $\mathrm{PTH} / \mathrm{PTH} \mathrm{rP}$, SP3/SP1, GADD45 $\beta$, MEF-2C, HIF-2a, SOX9, HDAC inhibitors, and the Ihh, Wnt or Bmp signaling pathways that have been reviewed recently. ${ }^{2}$ More importantly, most of the above factors/pathways show interaction with Runx2 and affect Col10a1 expression and chondrocyte hypertrophy. ${ }^{2}$ In our current studies, by dissecting the Col10a1 cis-enhancer, we identified multiple candidate Col10a1-interacting factors, including Cox-2 that has been shown to directly interact with Runx2. ${ }^{72}$ Indeed, candidate EMSA assays suggested that both Cox-2 and Runx2 are components of the specific binding complex (Figure 6). ${ }^{38}$ As Cox2 lacks DNA-binding site, suggesting that additional components exist in the binding complex. Given the direct interaction between Cox-2 and Runx2, we speculate that Cox-2 may act as a co-factor to interact with Runx2, which has DNA-binding capability, together to achieve their control over Col10a1 expression and chondrocyte hypertrophy. ${ }^{60,72}$ There are also known repressors (such as Sox9) that have been associated with Runx2 together to regulate Col10a1 expression, possibly by direct interaction, as both Runx2 and Sox9 sites are found adjacent each other within the Col10a1 enhancer. ${ }^{2,38,73}$ In addition, some candidate repressors (such as Nfat) we identified show interaction with Runx2 and have a role in Col10a1 expression and osteoarthritis development. ${ }^{74,75}$ Together, our data support that multiple factors, including transactivators, repressors and co-factors, work with Runx2 to regulate Col10a1 expression and chondrocyte hypertrophy. We believe Col10a1 trans-activators are promoters of chondrocyte hypertrophy and are targets for low bone growth as seen in skeletal dysplasia, whereas repressors will decrease Col10a1 expression and delay chondrocyte hypertrophy and are, therefore, targets for bone over growth as seen in osteophyte formation in osteoarthritis. We also believe that the candidate Col10a1 regulators identified by comprehensive biochemical, bioinformatics, proteomics and TG approaches as described in the article constitute unique resources. Further characterization of these candidate Col10a1 regulators will open up new avenues of research that aims to better understanding skeletal developmental and disease mechanisms and may hold promise for pharmaceutical purpose to develop therapeutic targets for relevant skeletal diseases.

\section{Materials and Methods}

Histochemical analysis of Col10a1-reporter TG mice. Tg mice that use the large Col10a1 promoter/intron and enhancer elements to drive LacZ gene as a reporter were generated as previously described. ${ }^{37}$ Specifically, the $\mathrm{Tg}-10 \mathrm{~kb}$ TG construct contains a 6-kb Col10a1 promoter and the large second intron (-6022 to $+4220 \mathrm{bp}$ ) upstream of the $\operatorname{Lac} Z$ gene. The $T g-4 \times 150 \mathrm{bp}$ construct utilizes four copies of the 150-bp Col10a1 enhancer (-4296 to $-4147 \mathrm{bp}$ ) and the basal promoter $(-220$ to $+110 \mathrm{bp})$ to drive the $\mathrm{LacZ}$ gene. Mouse embryos at the E15.5 (embryonic day 15.5) and P1 (postnatal day 1) stages from these two TG mouse lines were X-gal stained and compared for LacZ reporter expression. The limbs of these mouse embryos were paraffin embedded, sectioned and counterstained with nuclear fast red (Poly Scientific R\&D Corp., Bay Shore, NY, USA). At least 30 sections of the growth plate and adjacent tissues were analyzed. Comparison was among littermates within same mouse line or between mouse lines at the same developmental stage (E15.5 or P1). The studies were approved by the animal care and oversight committee at Rush University Medical Center.

In silico sequence analysis of Col10a1 cis-enhancer. The 150-bp Col10a1 enhancer (-4296 to $-4147 \mathrm{bp}$ ) was subjected to in silico sequence analysis to search for TFBS using following web-based programs: (1) TFSEARCH: the TFSEARCH tool was used to search for potential TFBS with a cutoff score of 85..$^{39,40}$ The web address for TFSEARCH is at http://www.cbrc.jp/research/db/ TFSEARCH.html. (2) Promo 3.0: Promo uses the TRANSFAC database (version 8.3) to identify TFBS in a given DNA sequence. ${ }^{41,42}$ The web address can be accessed at http://alggen.Isi.upc.es/cgi-bin/promo_v3/promo/promoinit.cgi?dirDB = TF_8.3. The searching result of potential TFBS will be displayed through a graphical interface or as a downloadable text file. (3) Transcription factor affinity prediction (TRAP): TRAP is used to predict which TFs are susceptible to bind a promoter with highest affinity. ${ }^{43}$ TRAP uses the TRANSFAC database and the searching result is listed in a table ranking the affinity of TFs with a $P$-value. TRAP is available at http://trap.molgen.mpg.de/cgi-bin/home.cgi. (4) MATCH: Match is a weight matrix-based program for predicting TFBS. ${ }^{44,45}$ With a courtesy of BIOBASE, we were able to use the TRANSFAC Professional database (version 10.1, January 2013). The address is at http://www.biobase-international.com/ product/transcription-factor-binding-sites.

Y1H screening. The 150-bp Col10a1 enhancer was used as bait to screen for its binding factors from a CDNA library derived from hypertrophic MCT cells using the BD Matchmaker One-Hybrid System (Clontech, K1617-1) and the manufacturer suggested protocol with modifications. Specifically, the bait construct pHis2.1-2 $\times 150$ was generated by cloning tandem copies of the 150-bp enhancer $(2 \times 150)$ into the Mlul site of pHis2.1, a one-hybrid vector containing the nutritional reporter gene HIS3 (Clontech, K1617-1). Detailed cloning strategy is available upon request. The cDNA library was generated using the BD SMART technology. The double strand (ds) cDNA derived from $1 \mu \mathrm{g}$ of total RNA of hypertrophic MCT cells was amplified by long-distance (LD)-PCR using vector-specific primers and was purified using the BD CHROMO SPIN Columns (Clontech, K1617-1). The Y187 yeast competent cells were prepared using manufacturer suggested protocol. Leaky expression of target-HIS3 reporter (pHis2.1 $2 \times 150$ ) was suppressed by selective medium and 3-amino-1,2,4-triazole (3'-AT, Sigma, St. Louis, MO, USA). The GAL4 $\mathrm{AD}$ fusion library constructing and screening for one-hybrid interaction (target ciselement and its binding factors) was carried out by co-transformation of the BD SMART ds CDNA, the bait reporter construct pHis2.1 $-2 \times 150$, linearized pGADT7Rec2 expression vector (PT3530-5, Clontech), and the pre-prepared Y187 yeast competent cells. Transformants that grow in selective medium (S.D./-His/-Leu/-Trp) and optimal 3-AT concentration $(100 \mu \mathrm{M})$ were harvested and subjected to PCR amplification using the Matchmaker Insert Check PCR Mix2 kit (cat. no. 630497, Clontech). PCR product was sequenced at the DNA Service Core at University of Illinois at Chicago using T7 primer or pGADT7-Rec2 expression vector-specific primers (Clontech). Sequence analysis and gene ID identification was carried out according to the National Center for Biotechnology Information (NCBI) database.

Mass spectrometry analysis of DNA-binding complex. The DNA/ protein complex formed by the Col10a1 cis-enhancer ( -4196 to -4172 bp) and the hypertrophic MCT cell nuclear extracts were analyzed by tandem mass 
spectrometry at the Proteomic and Biomarkers Core Facilities at Rush University Medical Center. ${ }^{38}$ The enhancer and its complementary oligo containing the tandem-repeat Runx2 sites (underlined: 5'-GATCCACAATTAGGTGTG GGTGTGGCCAGCA-3') were synthesized with or without $5^{\prime}$-biotinylateion (IDT Technology, Coralville, IA, USA). The oligos were then annealed and incubated with $200 \mu \mathrm{gs}$ of MCT cell nuclear extracts for $1 \mathrm{~h}$ at room temperature. This binding mixture was further incubated with streptavidin-conjugated magnetic particles $(50 \mu \mathrm{l}$, Invitrogen Corp., Carlsbad, CA, USA) to allow for efficient affinity pull-down of putative binding proteins. Proteins were eluted from the magnetic particles by addition of $40 \%$ methanol containing $0.1 \%$ formic acid. The protein elutes were then subjected to concentration via lyophilization and resuspended in $0.5 \mathrm{M}$ guanidine $\mathrm{HCl}$ in PBS (pH 7.4). After digestion with sequencing grade trypsin (Promega Corp., Madison, WI, USA) for $24 \mathrm{~h}$ at $37^{\circ} \mathrm{C}$, the digested materials were spotted with $1 \mu \mathrm{l}$ of $1 \mathrm{mg} / \mathrm{ml}$ CHCA in $0.1 \%$ TFA and analyzed on an AXIMA QIT (Shimadzu Corp., Columbia, MD, USA) for protein identification. All runs were performed with technical replicates to ensure reproducibility of the data. Data analysis was carried out using the Mascot software platform (Matrix Science, London, UK). The SwissProt 51.6 (protein) database was searched with following parameters: Rodentia database, monoisotopic tryptic peptides only, peptide mass tolerance at $\pm 2 \mathrm{Da}$, fragment mass tolerance at $\pm 1.5 \mathrm{Da}$ and maximum missed cleavages at 3 . A decoy database was also searched to eliminate false-positive proteins. Confidence of protein identification was filtered to have a minimum MASCOT score of 35 and at least five matched peptides per protein identification.

Candidate EMSAs. Candidate EMSA was performed using the LightShift Chemiluminescent EMSA kit (PIERCE, Rockford, IL, USA) with Cox-2 (H-62, sc-7951, Santa Cruz Biotechnology, Santa Cruz, CA, USA) and Nedd4 (A-16, sc-14429, Santa Cruz Biotechnology) antibodies. Shortly, the same Col10a1 cis-enhancer and its complementary DNA oligos were annealed and incubated with $5 \mu \mathrm{g}$ of the MCT cell nuclear extracts with or without a series of diluted Cox-2 or Nedd4 antibody (at doses of $0,0.2,0.5$ and $1 \mu \mathrm{g}$, respectively) at room temperature for $20 \mathrm{~min}$. The $5^{\prime}$-biotin-labeled and annealed oligos were then added to the binding mixture and further incubated for $30 \mathrm{~min}$. The mismatched DNA sequence and non-biotin-labeled competitor control, the binding condition and the amount of probes used for EMSA were as previously described. ${ }^{38}$ After electrophoresis, the binding mixture within the gel was transferred to a positively charged Nylon membrane (Thermo Scientific, Rockford, IL, USA; cat. no. 77016). Detection of the biotin-labeled DNA using stabilized streptavidin-HRP conjugate and the chemiluminescent substrate module was performed according to manufacturer suggested protocol (PIERCE, cat. no. 89880). Visualization of the binding complex was to expose the membrane to X-ray film and the CCD camera of Alphalmager (Alpha Innotech, San Leandro, CA, USA).

ChIP experiment. ChIP using MCT cells and Cox-2 antibody (sc-7951) was carried out using the Pierce Agarose ChIP Kit (cat. no. 26156, Thermo Scientific) as described. ${ }^{38}$ Briefly, sub-confluent MCT cells grown at $32{ }^{\circ} \mathrm{C}$ were further incubated at $37^{\circ} \mathrm{C}$ for additional 3 days. These cells were then cross-linked by $1 \%$ formaldehyde for $10 \mathrm{~min}$ at room temperature before addition of glycine to quench cross-linking. After harvest, cells were treated with $\mathrm{S} 1$ nuclease to shear chromatin DNA to majorly 200-400 bp. Immunoprecipitation was conducted using $10 \%$ of total pre-cleared chromatin (input sample) and $5 \mu \mathrm{g}$ each of the Cox-2 antibody or control $\operatorname{lgG}$. The cross-linked and precipitated protein mixtures were then subjected to proteinase $\mathrm{K}$ digestion and reverse cross-linking to allow for DNA purification. Semiquantitative and real-time PCR using DNA elutes and specific primers flanking the Col10a1 cis-enhancer (forward: 5'-CTGAACAGCTCCGAGGAAAC-3', reverse: $5^{\prime}$-TGGATATTCAGCCCTTTTGG-3') and associated intron II (forward: $5^{\prime}$-AATG ATGCATGGAAACGACA-3', reverse: $5^{\prime}$-GCCTATGCAATTGTTTTTAGCTT- $3^{\prime}$ ) were performed, as described. ${ }^{38}$ Data of real-time PCR is collected from multiple runs with duplicate templates. $P<0.05$ implies significant enrichment of target sequence using Cox-2 antibody.

Cell culture, RNA extraction and qRT-PCR. MCT cells were cultured at $32{ }^{\circ} \mathrm{C}$ in standard DME media with $8 \%$ fetal bovine serum and $8 \% \mathrm{CO}_{2}$ as described ${ }^{46} \mathrm{MCT}$ cells grown at $32{ }^{\circ} \mathrm{C}$ and reached $70-80 \%$ confluence were further cultured at $37^{\circ} \mathrm{C}$ for additional 3 days to obtain hypertrophic property. These cells were harvested for total RNA preparation using Trizol (Invitrogen Corp.). These total RNAs were subjected to first-strand cDNA synthesisis using Superscript III reverse transcriptase (Invitrogen Corp.). Quantitative real-time PCR was performed using the MyiQ Single Color Real-Time PCR Detection System and SYBR Green master mix (Bio-Rad, Hercules, CA, USA). Gene-specific primers for Gapdh, Col10a, Runx2, as well as candidate Col10a1 regulators were listed in primer tables 1, 2 and 3 respectively (Supplementary Data S6). Gapdh was used as an internal control of RNA quality. Col10a1 and Runx2 were analyzed to confirm the upregulation of Col10a1 and the hypertrophic property of MCT cells. The mean CT (threshold cycle number) values indicating relative transcript levels of target genes were normalized to Gapdh and were analyzed using $2^{-\Delta \Delta} \mathrm{Ct}$ method and student $t$-test. ${ }^{36,47}$ Data are collected from multiple runs with duplicate templates. $P<0.05$ implies significant fold change of target genes in hypertrophic MCT cells.

IHC analysis. Sagittal sections of mouse hind limbs at the age of E17.5 and 4 weeks were subjected to IHC analysis using Cox-2 (H-62, sc-7951, Santa Cruz) and collagen X (E-14, sc-323750, Santa Cruz) antibodies. Briefly, paraffinembedded limb sections undergone de-paraffin and rehydration were subjected to antigen retrieval by incubation with hot $\left(95^{\circ} \mathrm{C}\right)$ sodium citrate buffer $(0.01 \mathrm{M}, \mathrm{pH} 6.0)$ for $10 \mathrm{~min}$. The tissue sections were then exposed to hydrogen peroxide $\left(3 \% \mathrm{H}_{2} \mathrm{O}_{2}\right)$ for $5 \mathrm{~min}$ to quench the endogenous peroxidase, followed by blocking with $30 \%$ horse serum $(30 \mathrm{~min})$. The slides were incubated overnight with above primary Cox-2 or collagen $X$ antibodies $\left(1: 50\right.$ dilution) at $4{ }^{\circ} \mathrm{C}$. Non-immune mouse $\lg \mathrm{G}$ was used as a negative control. After washing with the 1XTBST (Tris Buffered Saline with $0.1 \%$ Tween-20), the slides were further incubated with biotinylated secondary antibody (anti-rabbit IgG, Santa Cruz) and detected using the ABC kit (Elite PK-6200 Universal, VECTOR Laboratories, Burlingame, CA, USA). Slides were counterstained with nuclear fast red (Poly Scientific R\&D Corp.) and analyzed using Nikon Eclipse 80i, (Nikon Instruments Inc., Melville, NY, USA) and the Qcapture Suite software (version, 2.95.0, Quantitative Imaging Corp., Surrey, BC, Canada).

\section{Conflict of Interest}

The authors declare no conflict of interest.

Acknowledgements. We are grateful to Drs. Rick Sumner, Meghan, Moran and Mr David Karwo for histological help on TG mice at the Rush Histology Core. The MCT cell model was a gift from Dr. Benoit de Crombrugghe from MD Anderson Cancer Center. This work was supported by the American Cancer Society-IL (no. 254598, QZ, YL), the NIH/NCl (R21CA161461, QZ), the Innovation Program of Jiangsu Province (no. 480, 2013, QZ) and the NSFC (nos. 31271399, 31440058 and 81472047, QZ, JG, YL).

1. Mackie EJ, Ahmed YA, Tatarczuch L, Chen KS, Mirams M. Endochondral ossification: how cartilage is converted into bone in the developing skeleton. Int J Biochem Cell Biol 2008; 40: $46-62$.

2. Lu Y, Qiao L, Lei G, Mira RR, Gu J, Zheng Q. Col10a1 gene expression and chondrocyte hypertrophy during skeletal development and disease. Front Biol 2014; 9 : 195-204.

3. Kronenberg HM. Developmental regulation of the growth plate. Nature 2003; 423: 332-336.

4. Shen $G$. The role of type $X$ collagen in facilitating and regulating endochondral ossification of articular cartilage. Orthod Craniofac Res 2005; 8: 11-17.

5. Grskovic I, Kutsch A, Frie C, Groma G, Stermann J, Schlötzer-Schrehardt U et al. Depletion of annexin $A 5$, annexin $A 6$, and collagen $X$ causes no gross changes in matrix vesiclemediated mineralization, but lack of collagen $X$ affects hematopoiesis and the Th1/Th2 response. J Bone Miner Res 2012; 27: 2399-2412.

6. Warman ML, Abbott M, Apte SS, Hefferon T, McIntosh I, Cohn DH et al. A type X collagen mutation causes Schmid metaphyseal chondrodysplasia. Nat Genet 1993; 5: 79-82.

7. von der Mark K, Frischholz S, Aigner T, Beier F, Belke J, Erdmann S et al. Upregulation of type $X$ collagen expression in osteoarthritic cartilage. Acta Orthop Scand Suppl 1995; 266: 125-129.

8. Girkontaite I, Frischholz S, Lammi P, Wagner K, Swoboda B, Aigner T et al. Immunolocalization of type $X$ collagen in normal fetal and adult osteoarthritic cartilage with monoclonal antibodies. Matrix Biol 1996; 15: 231-238.

9. Ikegawa S, Nishimura G, Nagai T, Hasegawa T, Ohashi H, Nakamura Y. Mutation of the type $\mathrm{X}$ collagen gene (COL10A1) causes spondylometaphyseal dysplasia. Am J Hum Genet 1998; 63: 1659-1662.

10. Drissi H, Zuscik M, Rosier R, O'Keefe R. Transcriptional regulation of chondrocyte maturation: potential involvement of transcription factors in OA pathogenesis. Mol Aspects Med. 2005; 26: 169-179.

11. Zheng Q, Sebald E, Zhou G, Chen Y, Wilcox W, Lee B et al. Dysregulation of chondrogenesis in human cleidocranial dysplasia. Am J Hum Genet 2005; 77: 305-312.

12. Tchetina EV, Di Battista JA, Zukor DJ, Antoniou J, Poole AR. Prostaglandin PGE2 at very low concentrations suppresses collagen cleavage in cultured human osteoarthritic articular cartilage: this involves a decrease in expression of proinflammatory genes, 
collagenases and COL10A1, a gene linked to chondrocyte hypertrophy. Arthritis Res Ther 2007; 9: R75.

13. Saito T, Fukai A, Mabuchi A, Ikeda T, Yano F, Ohba S et al. Transcriptional regulation of endochondral ossification by HIF-2alpha during skeletal growth and osteoarthritisdevelopment. Nat Med 2010; 16: 678-686.

14. Lamas JR, Rodríguez-Rodríguez L, Vigo AG, Alvarez-Lafuente R, López-Romero P, Marco $\mathrm{F}$ et al. Large-scale gene expression in bone marrow mesenchymal stem cells: a putative role for COL10A1 in osteoarthritis. Ann Rheum Dis 2010; 69: 1880-1885.

15. Dreier R. Hypertrophic differentiation of chondrocytes in osteoarthritis: the developmental aspect of degenerative joint disorders. Arthritis Res Ther 2010; 26: 216-227.

16. Wallis GA, Rash B, Sweetman WA, Thomas JT, Super M, Evans G et al. Amino acid substitutions of conserved residues in the carboxyl-terminal domain of the alpha $1(X)$ chain of type $\mathrm{X}$ collagen occur in two unrelated families with metaphyseal chondrodysplasia type Schmid. Am J Hum Genet 1994; 54: 169-178.

17. Mclntosh I, Abbott MH, Francomano CA. Concentration of mutations causing Schmid metaphyseal chondrodysplasia in the C-terminal noncollagenous domain of type $\mathrm{X}$ collagen. Hum Mutat 1995; 5: 121-125.

18. Kwan KM, Pang MK, Zhou S, Cowan SK, Kong RY, Pfordte T et al. Abnormal compartmentalization of cartilage matrix components in mice lacking collagen $\mathrm{X}$ : implications for function. J Cell Biol 1997; 136: 459-471.

19. Lee B, Thirunavukkarasu K, Zhou L, Pastore L, Baldini A, Hecht J et al. Missense mutations abolishing DNA binding of the osteoblast-specific transcription factor OSF2/CBFA1 in cleidocranial dysplasia. Nat Genet 1997; 16: 307-310.

20. Otto F, Thornell AP, Crompton T, Denzel A, Gilmour KC, Rosewell IR et al. Cbfa1, a candidate gene for cleidocranial dysplasia syndrome, is essential for osteoblast differentiation and bone development. Cell 1997; 89: 765-771.

21. Komori T, Yagi H, Nomura S, Yamaguchi A, Sasaki K, Deguchi K et al. Targeted disruption of Cbfa1 results in a complete lack of bone formation owing to maturational arrest of osteoblasts. Cell 1997; 89: 755-764.

22. Zhou G, Chen Y, Zhou L, Thirunavukkarasu K, Hecht J, Chitayat D et al. CBFA1 mutation analysis and functional correlation with phenotypic variability in cleidocranial dysplasia. Hum Mol Genet 1999; 8: 2311-2316.

23. Kim IS, Otto F, Zabel B, Mundlos S. Regulation of chondrocyte differentiation by Cbfa1. Mech Dev 1999; 80: 159-170.

24. Inada M, Yasui T, Nomura S, Miyake S, Deguchi K, Himeno M et al. Maturational disturbance of chondrocytes in Cbfa1-deficient mice. Dev Dyn 1999; 214: 279-290.

25. Mwale F, Girard-Lauriault PL, Wang HT, Lerouge S, Antoniou J, Wertheimer MR. Suppression of genes related to hypertrophy and osteogenesis in committed human mesenchymal stem cells cultured on novel nitrogen-rich plasma polymer coatings. Tissue Eng 2006; 12: 2639-2647.

26. Petit A, Wang HT, Girard-Lauriault PL, Wertheimer MR, Antoniou J, Mwale F. Novel insights into the mechanism of decreased expression of type $X$ collagen in human mesenchymal stem cells from patients with osteoarthritis cultured on nitrogen-rich plasma polymers: implication of cyclooxygenase-1. J Biomed Mater Res A 2010; 94: 744-750.

27. Riemer S, Gebhard S, Beier F, Poschl E, Von Der Mark K. Role of c-fos in the regulation of type $X$ collagen gene expression by PTH and PTHrP: Localization of a PTH/PTHrP-responsive region in the human COL10A1 enhancer. J Cell Biochem 2002; 86: 688-699.

28. Magee C, Nurminskaya M, Faverman L, Galera P, Linsenmayer TF. SP3/SP1 transcription activity regulates specific expression of collagen typeX in hypertrophic chondrocytes. J Biol Chem 2005; 280: 25331-25338.

29. Ijiri K, Zerbini LF, Peng H, Correa RG, Lu B, Walsh N et al. A novel role for GADD45beta as a mediator of MMP-13 gene expression during chondrocyte terminal differentiation. $J$ Biol Chem 2005; 280: 38544-38555.

30. Arnold MA, Kim Y, Czubryt MP, Phan D, McAnally J, Qi X et al. MEF2C transcription factor controls chondrocyte hypertrophy and bone development. Dev Cell 2007; 12 : 377-389.

31. Dy $P$, Wang W, Bhattaram P, Wang Q, Wang L, Ballock RT et al. Sox9 directs hypertrophic maturation and blocks osteoblast differentiation of growth plate chondrocytes. Dev Cell 2012; 22: 597-609.

32. Maruyama T, Miyamoto Y, Yamamoto G, Yamada A, Yoshimura K, Suzawa T et al. Downregulation of carbonic anhydrase IX promotes Col10a1 expression in chondrocytes. PLoS One 2013; 8: e56984.

33. Adams SL, Pallante K M, Niu Z, Cohen AJ, Lu J, LeBoy PS. Stimulation of type-X collagen gene transcription by retinoids occurs in part through the BMP signaling pathway. $J$ Bone Joint Surg Am 2003; 85-A: 29-33.

34. Dong Y, Drissi H, Chen M, Chen D, Zuscik MJ, Schwarz EM et al. Wnt-mediated regulation of chondrocyte maturation: Modulation by TGF-beta. J Cell Biochem 2005; 95: 1057-1068.

35. Schipani E, Provot S. PTHrP, PTH, and the PTH/PTHrP receptor in endochondral bone development. Birth Defects Res C Embryo Today 2003; 69: 352-362.

36. Zheng Q, Zhou G, Morello R, Chen Y, Garcia-Rojas X, Lee B. Type X collagen gene regulation by Runx2 contributes directly to its hypertrophic chondrocyte-specific expression in vivo. J Cell Biol 2003; 162: 833-842.

37. Zheng Q, Keller B, Zhou G, Napierala D, Chen Y, Zabel B et al. Localization of the cisenhancer element for mouse type $X$ collagen expression in hypertrophic chondrocytes in vivo. J Bone Miner Res 2009; 24: 1022-1032.
38. Li F, Lu Y, Ding M, Napierala D, Abbassi S, Chen Y et al. Runx2 contributes to murine Col10a1 gene regulation through direct interaction with its cis-enhancer. J Bone Miner Res 2011; 26: 2899-2910.

39. Heinemeyer T, Wingender E, Reuter I, Hermjakob H, Kel AE, Kel OV et al. Database on transcriptional regulation: TRANSFAC, TRRD and COMPEL. Nucleic Acids Res 1998; 26: 362-367.

40. Vares G, Uehara Y, Ono T, Nakajima T, Wang B, Taki K et al. Transcription factor-recognition sequences potentially involved in modulation of gene expression after exposure to low-doserate $\gamma$-rays in the mouse liver. J Radiat Res 2011; 52: 249-256.

41. Messeguer X, Escudero R, Farré D, Núñez O, Martínez J, Albà MM. PROMO: detection of known transcription regulatory elements using species-tailored searches. Bioinformatics 2002; 18: 333-334.

42. Farré $D$, Roset R, Huerta M, Adsuara JE, Roselló L, Albà MM et al. Identification of patterns in biological sequences at the ALGGEN server: PROMOand MALGEN. Nucleic Acids Res 2003; 31: 3651-3653.

43. Thomas-Chollier M, Hufton A, Heinig M, O'Keeffe S, Masri NE, Roider HG et al. Transcription factor binding predictions using TRAP for the analysis of ChIP- seq data and regulatory SNPs. Nat Protoc 2011; 6: 1860-1869.

44. Kel AE, Gössling E, Reuter I, Cheremushkin E, Kel-Margoulis OV, Wingender E. MATCH: a tool for searching transcription factor binding sites in DNA sequences. Nucleic Acids Res 2003; 31: 3576-3579.

45. Miller AK, Print CG, Nielsen PM, Crampin EJ. Hox genes regulate the onset of Tbx5 expression in the forelimb. PLoS One 2010; 5: e13897.

46. Lefebvre V, Garofalo S, de Crombrugghe B. Type X collagen gene expression in mouse chondrocytes immortalized by a temperaturesensitive simian virus 40 large tumor antigen. $J$ Cell Biol 1995; 128: 239-245.

47. Pfaffl MW. A new mathematical model for relative quantification in real-time RT-PCR. Nucleic Acids Res 2001; 29: e45.

48. Beier F, Vornehm S, Pöschl E, von der Mark K, Lammi MJ. Localization of silencer and enhancer elements in the human type X collagen gene. J Cell Biochem 1997; 66: 210-218.

49. Long $\mathrm{F}$, Sonenshein GE, Linsenmayer TF. Multiple transcriptional elements in the avian type $\mathrm{X}$ collagen gene. Identification of Sp1 family proteins as regulators for high level expression in hypertrophic chondrocytes. J Biol Chem 1998; 273: 6542-6549.

50. Volk SW, Luvalle P, Leask T, Leboy PS. A BMP responsive transcriptional region in the chicken type X collagen gene. J Bone Miner Res 1998; 13: 1521-1529.

51. Gebhard S, Poschl E, Riemer S, Bauer E, Hattori T, Eberspaecher $\mathrm{H}$ et al. A highly conserved enhancer in mammalian type $X$ collagen genes drives high levels of tissuespecific expression in hypertrophic cartilage in vitro and in vivo. Matrix Biol 2004; 23 : 309-322.

52. Sandelin A. Prediction of regulatory elements. Methods Mol Biol 2008; 453: 233-244.

53. Wingender $\mathrm{E}$, Dietze $\mathrm{P}$, Karas $\mathrm{H}$, Knüppel R. TRANSFAC: a database on transcription factors and their DNA binding sites. Nucleic Acids Res 1996; 24: 238-241.

54. Wu S, Flint JK, Rezvani G, De Luca F. Nuclear factor-kappaB p65 facilitates longitudinal bone growth by inducing growth plate chondrocyte proliferation and differentiation and by preventing apoptosis. J Biol Chem 2007; 282: 33698-33706.

55. Wingender E, Chen X, Fricke E, Geffers R, Hehl R, Liebich I et al. The TRANSFAC system on gene expression regulation. Nucleic Acids Res 2001; 29: 281-283.

56. Moritani NH, Kubota S, Eguchi T, Fukunaga T, Yamashiro T, Takano-Yamamoto T et al. Interaction of AP-1 and the ctgf gene: a possible driver of chondrocyte hypertrophy in growth cartilage. J Bone Miner Metab 2003; 21: 205-210.

57. Lengner CJ, Lepper C, van Wijnen AJ, Stein JL, Stein GS, Lian JB. Primary mouse embryonic fibroblasts: a model of mesenchymal cartilage formation. J Cell Physiol 2004; 200: 327-333.

58. Agueda L, Bustamante M, Jurado S, Garcia-Giralt N, Ciria M, Saló G et al. A haplotype-based analysis of the LRP5 gene in relation to osteoporosis phenotypes in Spanish postmenopausal women. J Bone Miner Res 2008; 23: 1954-1963.

59. Minguillon C, Nishimoto S, Wood S, Vendrell E, Gibson-Brown JJ, Logan MP. A Bayesian search for transcriptional motifs. Development 2012; 139: 3180-3188.

60. Welting TJ, Caron MM, Emans PJ, Janssen MP, Sanen K, Coolsen MM et al. Inhibition of cyclooxygenase-2 impacts chondrocyte hypertrophic differentiation during endochondral ossification. Eur Cell Mater 2011; 22: 420-436.

61. Mikic B, Ferreira MP, Battaglia TC, Hunziker EB. Accelerated hypertrophic chondrocyte kinetics in GDF-7 deficient murine tibial growth plates. J Orthop Res 2008; 26: 986-990.

62. LeClair EE, Bonfiglio L, Tuan RS. Expression of the paired-box genes Pax-1 and Pax-9 in limb skeleton development. Dev Dyn 1999; 214: 101-115.

63. Takimoto A, Mohri H, Kokubu C, Hiraki Y, Shukunami C. Pax1 acts as a negative regulator of chondrocyte maturation. Exp Cell Res 2013; 319: 3128-3139.

64. Weston AD, Underhill TM. Analysis of Nedd4 expression during skeletal development in the mouse limb. Mech Dev 2000; 94: 247-250.

65. Shukunami C, Ishizeki K, Atsumi T, Ohta Y, Suzuki F, Hiraki Y. Cellular hypertrophy and calcification of embryonal carcinoma-derived chondrogenic cell line ATDC5 in vitro. J Bone Miner Res 1997; 12: 1174-1188. 
66. Gu J, Lu Y, Qiao L, Ran D, Li N, Cao H, Gao Y, Zheng Q. Mouse p63 variants and chondrogenesis. Int J Clin Exp Pathol 2013; 6: 2872-2879 eCollection 2013.

67. Goodman S, Ma T, Trindade M, Ikenoue T, Matsuura I, Wong N et al. COX-2 selective NSAID decreases bone ingrowth in vivo. J Orthop Res 2002; 20: 1164-1169.

68. Zhang X, Schwarz EM, Young DA, Puzas JE, Rosier RN, O'Keefe RJ. Cyclooxygenase-2 regulates mesenchymal cell differentiation into the osteoblast lineage and is critically involved in bone repair. J Clin Invest 2002; 109: 1405-1415.

69. Drissi H, Li X, Sheu T, Zuscik MJ, Schwarz EM, Puzas JE et al. Runx2/Cbfa1 stimulation by retinoic acid is potentiated by BMP2 signaling through interaction with Smad1 on the collagen X promoter in chondrocytes. J Cell Biochem 2003; 90: 1287-1298.

70. Simões B, Conceição N, Viegas CS, Pinto JP, Gavaia PJ, Hurst LD et al. Identification of a promoter element within the zebrafish colXalpha1 gene responsive to runx2 isoforms Osf2 Cbfa1 and til-1 but not to pebp2alphaA2. Calcif Tissue Int 2006; 79: 230-244.

71. Higashikawa A, Saito T, Ikeda T, Kamekura S, Kawamura N, Kan A et al. Identification of the core element responsive to runt-related transcription factor 2 in the promoter of human type X collagen gene. Arthritis Rheum 2009; 60: 166-178.

72. Susperregui AR, Gamell C, Rodríguez-Carballo E, Ortuño MJ, Bartrons R, Rosa JL et al. Noncanonical BMP signaling regulates cyclooxygenase-2 transcription. Mol Endocrinol 2011; 25: 1006-1017.

73. Leung VY, Gao B, Leung KK, Melhado IG, Wynn SL, Au TY, Dung NW, Lau JY, Mak AC, Chan D, Cheah KS. SOX9 governs differentiation stage-specific gene expression in growth plate chondrocytes via direct concomitant transactivation and repression. PLoS Genet 2011; 7: e1002356

74. Zanotti S, Canalis E. Notch suppresses nuclear factor of activated T cells (NFAT) transactivation and Nfatc1 expression in chondrocytes. Endocrinology 2013; 154: 762-772.

75. Wang J, Gardner BM, Lu Q, Rodova M, Woodbury BG, Yost JG et al. Transcription factor Nfat1 deficiency causes osteoarthritis through dysfunction of adult articular chondrocytes. J Pathol 2009; 219: 163-172.

(c) (i) Cell Death and Disease is an open-access journal published by Nature Publishing Group. This work is licensed under a Creative Commons Attribution 4.0 International Licence. The images or other third party material in this article are included in the article's Creative Commons licence, unless indicated otherwise in the credit line; if the material is not included under the Creative Commons licence, users will need to obtain permission from the licence holder to reproduce the material. To view a copy of this licence, visit http://creativecommons.org/licenses/by/4.0

Supplementary Information accompanies this paper on Cell Death and Disease website (http://www.nature.com/cddis) 